\title{
Article \\ Arabidopsis Hypocotyl Adventitious Root Formation Is Suppressed by ABA Signaling
}

\author{
Yinwei Zeng ${ }^{1,+}$, Inge Verstraeten ${ }^{1,2,+}$, Hoang Khai Trinh ${ }^{1,+}{ }^{\dagger}$, Thomas Heugebaert ${ }^{3}$, Christian V. Stevens ${ }^{3}{ }^{(}$, \\ Irene Garcia-Maquilon ${ }^{4}$, Pedro L. Rodriguez ${ }^{4}\left(\mathbb{D}\right.$, Steffen Vanneste ${ }^{1,5,6}(\mathbb{D})$ and Danny Geelen $1, * \mathbb{(}$
}

1 Department Plants and Crops, Faculty of Bioscience Engineering, Ghent University, Coupure Links 653, 9000 Ghent, Belgium; Yinwei.Zeng@UGent.be (Y.Z.); inge.verstraeten@ist.ac.at (I.V.); HoangKhai.Trinh@UGent.be (H.K.T.); Steffen.Vanneste@ugent.be (S.V.)

2 Institute of Science and Technology (IST) Austria, Am Campus 1, 3400 Klosterneuburg, Austria

3 Department of Green Chemistry and Technology, Faculty of Bioscience Engineering, Ghent University, Coupure Links 653, 9000 Ghent, Belgium; Thomas.Heugebaert@Ugent.be (T.H.); Chris.Stevens@UGent.be (C.V.S.)

4 Instituto de Biologia Molecular y Celular de Plantas, Consejo Superior de Investigaciones Cientificas, Universidad Politecnica de Valencia, Avd de los Naranjos, 46022 Valencia, Spain; irene.gmaquilon@gmail.com (I.G.-M.); prodriguez@ibmcp.upv.es (P.L.R.)

5 Department of Plant Biotechnology and bioinformatics, Faculty of Sciences, Ghent University, Technologiepark 71, 9052 Ghent, Belgium

6 Lab of Plant Growth Analysis, Ghent University Global Campus, Incheon 21985, Korea

* Correspondence: danny.geelen@UGent.be; Tel.: +32-9-264-6070

check for updates

Citation: Zeng, Y.; Verstraeten, I.; Trinh, H.K.; Heugebaert, T.; Stevens, C.V.; Garcia-Maquilon, I.; Rodriguez, P.L.; Vanneste, S.; Geelen, D.

Arabidopsis Hypocotyl Adventitious Root Formation Is Suppressed by ABA Signaling. Genes 2021, 12, 1141. https://doi.org/10.3390/ genes12081141

Academic Editors: Viola Willemsen and Wouter Kohlen

Received: 31 May 2021

Accepted: 20 July 2021

Published: 27 July 2021

Publisher's Note: MDPI stays neutral with regard to jurisdictional claims in published maps and institutional affiliations.

Copyright: (c) 2021 by the authors. Licensee MDPI, Basel, Switzerland. This article is an open access article distributed under the terms and conditions of the Creative Commons Attribution (CC BY) license (https:/ / creativecommons.org/licenses/by/ $4.0 /)$.
+ These authors contributed equally.

\begin{abstract}
Roots are composed of different root types and, in the dicotyledonous Arabidopsis, typically consist of a primary root that branches into lateral roots. Adventitious roots emerge from non-root tissue and are formed upon wounding or other types of abiotic stress. Here, we investigated adventitious root (AR) formation in Arabidopsis hypocotyls under conditions of altered abscisic acid (ABA) signaling. Exogenously applied ABA suppressed AR formation at $0.25 \mu \mathrm{M}$ or higher doses. AR formation was less sensitive to the synthetic ABA analog pyrabactin (PB). However, $\mathrm{PB}$ was a more potent inhibitor at concentrations above $1 \mu \mathrm{M}$, suggesting that it was more selective in triggering a root inhibition response. Analysis of a series of phosphonamide and phosphonate pyrabactin analogs suggested that adventitious root formation and lateral root branching are differentially regulated by ABA signaling. ABA biosynthesis and signaling mutants affirmed a general inhibitory role of ABA and point to PYL1 and PYL2 as candidate ABA receptors that regulate AR inhibition.
\end{abstract}

Keywords: adventitious roots; abscisic acid; Arabidopsis thaliana

\section{Introduction}

Abscisic acid (ABA) plays an essential role in controlling the responses of plants to such abiotic stresses as high salinity, low temperature and drought [1,2]. Abiotic stress stimulates ABA synthesis and this triggers a variety of physiological and developmental adaptations $[3,4]$. Depending on different environmental cues and water availability, ABA regulates, for instance, stomatal transpiration as well as root hydrotropism, and, below ground, it controls root architecture [5-8]. Modulation of growth is a lasting effect and represents a durable solution for improving, for instance, drought tolerance of crops [9,10].

In plants, $\mathrm{ABA}$ is synthesized by the cleavage of carotenoids in the plastids involving zeaxanthin epoxidase (ABA1) and nine-cis-epoxycarotenoid dioxygenase (NCED) followed by two oxidation steps (ABA2 and AAO3/ABA3) in the cytoplasm [11]. ABA signaling involves long and short distance transport and perception by PYR/PYL/RCAR (PYRABACTIN RESISTANCE 1/PYR1-like/REGULATORY COMPONENTS OF ABA RECEPTOR) ABA receptors. Upon ABA binding, ABA receptors interact with and inhibit clade A type $2 \mathrm{C}$ protein phosphatases (PP2Cs), which are coreceptors in the ternary 
complex [12-14]. Both PYR/PYL/RCARs and clade A PP2Cs are encoded by gene families (14 and 9 members, respectively) and some of them can interact to form receptor complexes with specific, yet overlapping, regulatory functions $[5,12,15]$. The binding of ABA relieves the PP2C-mediated inhibition of SNF1-related protein kinases (SnRK2) SnRK2.2/2.3/2.6, which are further activated through phosphorylation of Ser171 and Ser175 residues (SnRK2.6 nomenclature) by B2/B3-type RAF kinases [16,17]. Phosphorylation of ion channels [18] and transcription factors by ABA-activated SnRK2s then results in multiple physiological and developmental responses [19-23]. Several transcription factors, such as ABI3, ABI4 and ABI5/ABRE-binding factors (ABFs), have been identified as key regulators of $\mathrm{ABA}$ signaling. $\mathrm{ABI} 3$ is a B3-type transcription factor, ABI4 is an AP2-type transcription factor and ABI5/ABFs are bZIP-type transcription factors. Only the ABI5 clade of bZIPs have been shown to be directly regulated by SnRK2 phosphorylation [24-26], while $\mathrm{ABI} 3$ and $\mathrm{ABI} 4$ are transcriptionally induced in response to $\mathrm{ABA}$, as a transcriptional target of the SnRK2 target RAV1 transcription factor [27,28].

ABA signaling by PYR/PYL/RCARs results in partial functional redundancy, which has precluded the direct identification of the ABA perception mechanism via forward genetic screens for ABA-insensitivity. Detailed analyses of different ABA responses have, nevertheless, led to the discovery of non-redundant functions for specific $\mathrm{ABA}$ receptors [29-33]. In contrast to $\mathrm{ABA}$, the $\mathrm{ABA}$ signaling agonist, pyrabactin ( $\mathrm{PB}$, has a higher degree of selectivity by binding to a subset of $A B A$ receptors $[34,35]$. This feature enabled the identification of the PYR/PYL/RCAR family of ABA receptors by using a chemical genetic approach for sidestepping genetic redundancy [12-14]. Interestingly, PB is an agonist for PYR1 and PYL1, but is an antagonist of PYL2 [35], thus explaining the differential bioactivities of $\mathrm{PB}$ and ABA. Subsequent research has led to the development of other synthetic agonists such as quinabactin [36] and opabactin [37] to improve selectivity and activity for certain receptors or enhance potency to trigger certain ABA-mediated biological effects [34,38,39].

Due to its important role in plant physiology and development, much research has focused on understanding the function of ABA in different developmental processes. This has resulted in the uncovering of multiple and complex effects of ABA signaling in the root. One prominent developmental ABA-sensitive growth response of the root is its ability to sense differences in water potential and translate this into growth towards water (hydrotropism). This response was found to depend on SnRK2.2 activity in the cortex [8], and is enhanced in quadruple loss-of-function pp2c mutants [29,40]. Additionally, when roots are not in contact with water as they enter a soil macropore, lateral root initiation is temporally inhibited to avoid developing lateral roots in the air (xerobranching response). This response is associated with PYR/PYL-dependent ABA signaling [7]. Moreover, inhibition of ABA signaling in the endodermis by overexpression of the dominant PP2C allele, abi1-1D, rendered lateral root primordium (LRP) development resistant to salt [41]. Consistently, LR growth was less sensitive to ABA inhibition in quadruple in pyr1pyl1,2,4, abi1-1 and snrk2.2/3/6 mutants [30]. The ABA-induced quiescence of LR primordia was found to depend on $P Y L 8$ and $P Y L 9$, which control auxin-responsive gene expression in LRPs via direct regulation of MYB77 and MYB44 transcriptional activities, independently of SnRK2-based ABA signaling [42,43].

The above examples indicate that the role of $\mathrm{ABA}$ in primary root (PR) growth and lateral root (LR) development is well investigated. In contrast, the role and signaling mechanism underlying ABA regulated adventitious root (AR), which form de novo from non-root tissues, development remains poorly characterized [44]. Here, we specifically focused on determining a first molecular framework for the ABA-regulated AR development after etiolation [45], in the model species Arabidopsis thaliana, to clarify the role of ABA during adventitious rooting. To this end, we combined phenotypic analyses in knockout lines impaired in $\mathrm{ABA}$ biosynthesis and signaling components and pharmacological applications of exogenous $\mathrm{ABA}$ and $\mathrm{ABA}$ - signaling agonists. We also developed novel $\mathrm{PB}$ analogues, bioisosteres of the sulfonamide moiety, namely phosphonamide and phosphonate substitu- 
tions [46]. These analogues could help to tell apart ABA- and pyrabactin-specific action mechanisms as both molecules have a different effect on AR formation. Our analyses unequivocally demonstrate that endogenous $\mathrm{ABA}$ levels suppress $\mathrm{AR}$ formation, and that this depends on canonical ABA signaling components.

\section{Materials and Methods}

\subsection{Plant Materials and Growth Conditions}

The aba1-1, aba3-1, pyr1-1, pyl1-1 (SALK_054640), pyl2-1 (CSHL_GT2864), pyl3 (SALK_073305), pyl4-1 (SAIL_517_C08), pyl5 (SM_3_3493), pyl8-1 (SAIL_1269_A02), pyl9 (SALK_083621), pyr1pyl1,4 (pyr1 pyl1 pyl4, abbreviated as 114), pyl1,4,5 (pyl1 pyl4 pyl5, abbreviated as 145), pyl1,4,8 (pyl1 pyl4 pyl8, abbreviated as 148), pyl4,5,8 (pyl4 pyl5 pyl8, abbreviated as 458), pyl1,4,5,8 (pyl1 pyl4 pyl5 pyl8, abbreviated as 1458), pyl1,2,4,5,8 (pyl1 pyl2 pyl4 pyl5 pyl8, abbreviated as 12458), pyr1pyl1,2,4,5,8 (pyr1 pyl1 pyl2 pyl4 pyl5 pyl8, abbreviated as 112458), and abi4-1 used in this study are in the Columbia-0 (Col-0) background. The aba2-1, abi1-1, abi2-1 and abi3-1 are in the Landsberg erecta (Ler) background. The single PYR1/PYL/RCAR receptor mutants were obtained from NASC (The Nottingham Arabidopsis Stock Centre). High-order pyl mutants have been reported previously [47]. Arabidopsis thaliana plants were incubated following the regime depicted in Figure S1. In brief: Seeds were surface sterilized and sown on 1/2 MS agar vertical plates $(1.5 \mathrm{~g} / \mathrm{L}$ MS, $0.5 \%(w / v)$ Sucrose, $0.05 \%(w / v)$ MES, and $0.8 \%(w / v)$ agar, $\mathrm{pH} 5.7$, described by Trinh et al. (2018) [45]). Plates were incubated for $4 \mathrm{~d}$ at $4{ }^{\circ} \mathrm{C}$ in the dark for stratification. Plants were germinated by $8 \mathrm{~h}$ incubation in the light $\left(22^{\circ} \mathrm{C}, 70 \mu \mathrm{mol} / \mathrm{m}^{2} \mathrm{~s}\right)$ before being incubated for $3 \mathrm{~d}$ in the dark to induce hypocotyl elongation. Well-elongated seedings were transferred to treatment and further grown on these plates for $10 \mathrm{~d}$ in a growth chamber at $70 \%$ relative humidity and $22{ }^{\circ} \mathrm{C}$, with $16 \mathrm{~h} / 8 \mathrm{~h}$ light/dark cycles $\left(70 \mu \mathrm{mol} / \mathrm{m}^{2} \mathrm{~s}\right)$. Chemicals were purchased from Sigma-Aldrich. Abscisic acid and pyrabactin were prepared as a $10 \mathrm{mM}$ stock solution in DMSO and stored at $-20^{\circ} \mathrm{C}$ until use. For dose-response analyses, appropriate volumes were added to autoclaved liquid medium and mixed before being transferred to $12 \times 12 \mathrm{~cm}$ square petri dishes [45]. Data were collected from at least three independent root growth experiments and analyzed using ANOVA statistics.

\subsection{General Procedure for the PB Analog Synthesis}

The synthesis of $\mathrm{PB}$ analogs was performed as previously described [46]. Diethyl ether and tetrahydrofuran were distilled from sodium benzophenone ketyl or sodium prior to use. Commercially available solvents and reagents were purchased from Sigma-Aldrich or Acros and used without further purification, unless stated otherwise. The purification of reaction mixtures was performed by column chromatography using a glass column filled with silica gel (Acros, particle size $0.035-0.070 \mathrm{~mm}$, pore diameter ca. $6 \mathrm{~nm}$ ). Solvent systems were determined via initial TLC analysis on glass plates, coated with silica gel (Merck, Kieselgel 60 F254, precoated $0.25 \mathrm{~mm}$ ). Visualisation of the compounds on TLC plates was performed by UV irradiation or coloration with $\mathrm{KMnO} 4$ solution or elemental iodine. High resolution 1H-NMR (300 MHz) and 13C-NMR $(75 \mathrm{MHz})$ spectra were run on a Jeol Eclipse FT 300 spectrometer at room temperature. Peak assignments were obtained with the aid of DEPT, 2D-HSQC and 2D-COSY spectra. The compounds were diluted in deuterated chloroform. Low resolution mass spectra were recorded via direct injection on an Agilent 1100 Series LC/MSD type SL mass spectrometer with electron spray ionisation geometry (ESI 70V) and using a mass selective detector (quadrupole). IR-spectra were obtained from a Perkin-Elmer BX FT-IR spectrometer. All compounds were analyzed in neat form with an ATR (Attenuated Total Reflectance) accessory.

\subsection{Genotyping}

DNA was extracted from individual progeny plants using an extraction buffer containing $100 \mathrm{mM}$ Tris- $\mathrm{HCl}, 500 \mathrm{mM} \mathrm{NaCl}, 50 \mathrm{mM}$ ethylenediaminetetraacetic acid (EDTA) and 
$0.7 \%$ sodium dodecyl sulphate (SDS) followed by a precipitation step in isopropanol. Afterwards, a double PCR reaction was carried out using a combination of wild-type primers and T-DNA-specific primers (Table S1). PCR reactions contained $10 \mathrm{ng}$ DNA, $1 \mu \mathrm{L}$ of DreamTaq ${ }^{\text {TM }}$ Green Buffer, 2.5 pmol forward and reverse primer, $250 \mu \mathrm{M}$ dNTPs and $0.1 \mu \mathrm{L}$ of DreamTaq ${ }^{\mathrm{TM}}$ DNA Polymerase, adjusted to a $10 \mu \mathrm{L}$ volume with water. Temperature cycling was $2 \min 95^{\circ} \mathrm{C}, 30 \mathrm{~s} 95^{\circ} \mathrm{C}, 30-35$ cycles of $30 \mathrm{~s} 95^{\circ} \mathrm{C}, 30 \mathrm{~s} 55^{\circ} \mathrm{C}, 1 \mathrm{~min} 72^{\circ} \mathrm{C}$, and $5 \mathrm{~min} 72{ }^{\circ} \mathrm{C}$. Visualization of the PCR products after gel electrophoresis confirmed the homo- or heterozygosity of the tested plants. Homozygous T-DNA insertion plants were used in further experiments.

\subsection{Phosphatase Activity Inhibition Assays}

Phosphatase activity was assayed using p-nitrophenyl phosphate (pNPP) as a substrate according to Belda-Palazon et al. (2018) [31]. Assays were performed in a $100 \mu \mathrm{L}$ reaction volume containing $25 \mathrm{mM}$ TRIS- $\mathrm{HCl}, \mathrm{pH} 7.5,10 \mathrm{mM} \mathrm{MgCl} 2,1 \mathrm{mM}$ dithiothreitol (DTT), $20 \mathrm{mM}$ pNPP, and $1 \mu \mathrm{M}$ of recombinant $\triangle \mathrm{NHAB} 1$ from Arabidopsis thaliana. Blank controls without recombinant ABA receptor (PYR1, PYL1) or without pyrabactin (DMSO) were included as a $100 \%$ phosphatase activity reference. Pyrabactin and pyrabactin analogs were applied at quantities of $10 \mu \mathrm{M}$ for the reaction, and the different ABA receptors (PYR1, PYL1) were added at a final concentration of $2 \mu \mathrm{M}$. Dephosphorylation of pNPP was monitored with a ViktorX5 reader at $405 \mathrm{~nm}$ for $60 \mathrm{~min}$ at $30^{\circ} \mathrm{C}$. To calculate PP2C activity, the final absorbance value was subtracted from the initial value and was expressed as percentage of phosphatase activity in the absence of ligand. Three independent experiments were performed, and values are averages $\pm \mathrm{SD}$. DMSO blank controls contained $1 \%(v / v)$ DMSO and correspond to $100 \%$ of phosphatase activity.

\subsection{Root Phenotypic Analysis}

The macrographs were taken with a Nikon D5000 camera and the images were analyzed with Image ${ }^{\circledR}$. The PR length was measured for individual seedlings via the Segmented Line tool, in which an estimated profile of the root was tracked, and the length of this profile was calculated. The lateral root and adventitious root were scored using a binocular microscope (Olympus, SZX9, Tokyo, Japan).

\subsection{Seed Germination Assay}

Arabidopsis thaliana seeds were collected at the same for germination assays. Seeds were surface sterilized and sown on $1 / 2$ MS medium (1.5 g / L MS, $0.5 \%(w / v)$ Sucrose, $0.05 \%(w / v)$ MES, and $0.8 \%(w / v)$ agar, $\mathrm{pH} 5.7)$ supplemented with $\mathrm{ABA}, \mathrm{PB}$, or PB analogs. Then, plates were stratified at $4{ }^{\circ} \mathrm{C}$ for 4 days in darkness. Seeds were germinated at $22{ }^{\circ} \mathrm{C}$ under $16 \mathrm{~h} \mathrm{light} / 8 \mathrm{~h}$ dark cycles $\left(70 \mu \mathrm{mol} / \mathrm{m}^{2} \mathrm{~s}\right)$. Germination was scored as a percentage representing the ratio of the number of germinated seeds (emergence of radicles, green cotyledon appearance) to the total seeds initially spread on the plate after 10 days.

\subsection{Statistical Analyses}

Statistical analysis was performed using the GraphPad Prism. One-way ANOVA was performed to determine significant differences between groups of samples, as indicated by different letters. Levels of significance are indicated in the figures by asterisks: ${ }^{*} p \leq 0.05$; ${ }^{* *} p \leq 0.01 ; * * * p \leq 0.001$. Values represent the mean of $25-40$ Arabidopsis plants in each graph and come from at least 2 independent plant cultures.

\section{Results and Discussion}

\subsection{Differential Inhibition of $A R$ and LR Formation by $A B A$ and Pyrabactin}

To investigate the control of ABA over root development, a series of in vitro experiments were set up to test for primary root growth, lateral root and hypocotyl adventitious root formation (Figure S1). Since ABA has a wide spectrum of activities when exogenously applied, the more selective, synthetic ABA analog pyrabactin was used for comparison [35]. 
ABA control over root growth is complex as it can both stimulate growth of the primary root and inhibit growth of lateral roots under salt stress conditions by signaling within the endodermal layer [47]. Consistent with the inhibition of primary root growth and cell expansion by exogenous ABA [48], primary root growth, adventitious root (AR) and lateral root (LR) formation were strongly inhibited in a dose-dependent manner (Figure 1). ABA impaired primary root growth at $2.5 \mu \mathrm{M}$ and above, while at least $10 \mu \mathrm{M}$ PB was required to show a significant reduction in root length (Figure 1A). At the lowest PB dose $(0.25 \mu \mathrm{M})$, primary root growth was significantly stimulated, in line with the earlier reports showing that $\mathrm{ABA}$ can stimulate growth of the primary root by signaling within the endodermal layer $[41,49]$. In contrast to the primary root, ABA and PB differentially regulated lateral and adventitious root formation (Figure 1). ABA inhibited LR formation at every concentration applied, whereas PB showed a biphasic dose dependence. Low doses of PB stimulated LR formation and, at $10 \mu \mathrm{M}$, the number of LR formed was reduced (Figure 1B). In our assay, etiolated seedlings are transferred to light conditions, stimulating AR formation to, on average, 1.4 AR per seedling (Figure 1C). ABA inhibited AR rooting, which is consistent with the reduction in AR formation in deepwater rice [50] and wheat grown under waterlogged conditions [51]. However, ABA and PB treatments produced a different dose-response curve: low doses of ABA inhibited AR formation more strongly than higher doses (Figure 1C), while PB was a more potent inhibitor, specifically at the higher doses (Figure 1C). The differential responses of three root structures analyzed reveal a complex regulation of root growth and architecture by ABA. Furthermore, it suggests that synthetic analogs of ABA, such as pyrabactin and derivatives, may be used to modulate root architecture to improve, for example, drought tolerance.

A

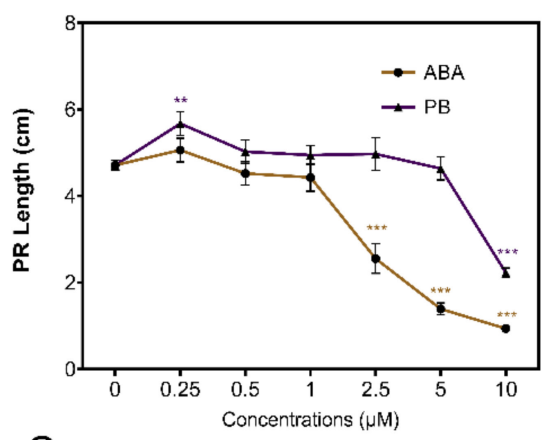

C

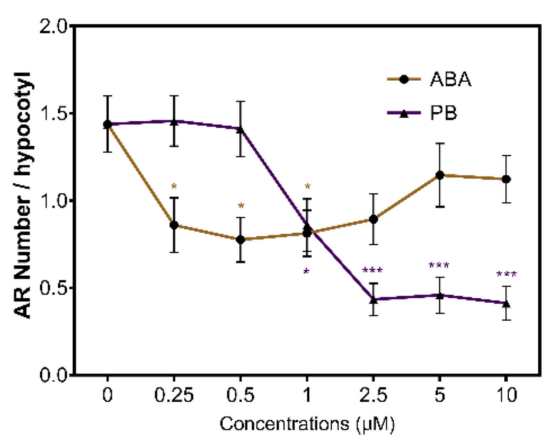

B

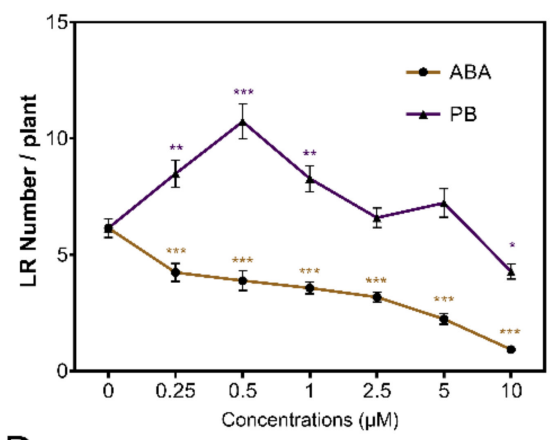

D

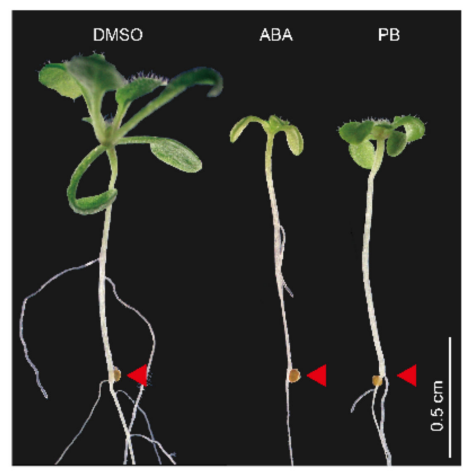

Figure 1. In vitro root development in response to exogenous application of $A B A$ and $P B$. (A-C) $\mathrm{ABA}$ and $\mathrm{PB}$ dose-response curves of primary root growth $(\mathbf{A})$, lateral root number per plant $(\mathbf{B})$ and adventitious root number per hypocotyl (C). ABA and PB was applied at concentrations from $0 \mu \mathrm{M}$ to $10 \mu \mathrm{M}$. (D) Adventitious root phenotype of Col-0 plants in the absence or presence of $10 \mu \mathrm{M} \mathrm{ABA}$ and $\mathrm{PB}$; photographs were taken 10 days after de-etiolation; the red triangle points to the hypocotyl root junction. $B a r=0.5 \mathrm{~cm}$. Data are represented as mean values \pm se and were obtained from plants grown in three independent experiments $(n=20-25)$. Statistics were calculated through ANOVA and levels of significance are represented as $\left({ }^{*}\right) p \leq 0.05,\left({ }^{* *}\right) p \leq 0.01,\left({ }^{* * *}\right) p \leq 0.001$. 
In a previous study, we synthesized phosphonamide (E1-E10) and phosphonate (D1-D3) pyrabactin analogues and showed these to reduce the stomatal aperture in tobacco leaf epidermal strips (Figure S2; [45]). These analogues were scored for their impact on germination, root and shoot development. Next to ABA and PB, the compounds E1, E4, E5, E6 and E7 showed activities that were scored as intermediate $(++)$ to strong $(+++)$ (Table S2). E1 and E5 were somewhat selective, with E1 reducing primary root length and LR number and E5 strongly inhibiting germination, and showing weak activity against primary root length and LR formation. E4, 6 and 7 were more broadly active, causing a more general strong reduction in growth. The effect of the pyrabactin analogues on root and shoot development was quantified, confirming that compounds E4, 6 and 7 strongly inhibited root and shoot growth (Figure S3). Although most compounds showed an inhibitory or no differential growth effect, some compounds stimulated root growth. The compounds E1 and D2 significantly stimulated AR formation and compound E8 stimulated primary root growth (Figure S3). The pharmacological study further confirmed that root growth differentially responds to ABA analogues; however, none of the compounds were sufficiently selective to control only one of the measured root parameters.

To further characterize the putative molecular activity of the pyrabactin analogs, in vitro phosphatase inhibition assays using the ABA receptor proteins AtPYR1 and AtPYL1 and the catalytic core of Arabidopsis HAB1 ( $\triangle \mathrm{NHAB1}$, amino acids 170-511) were performed. Overall, the activity of the analogs was very weak as compared to PB (Figure S5). E2 reduced PYR1- and E4 PYL1-mediated phosphatase activity, both by about $40 \%$, at a $10 \mu \mathrm{M}$ application dose. In view of the strong growth inhibition by E1, E5, E6 and E7 phosphonate analogs, these compounds evoke signaling through other PYR receptors than PYR1 and PYL1, or via other signaling routes. Alternatively, in vivo metabolism of these compounds might enhance their activity against PYR1/PYL1.

\subsection{Defects in the ABA Biosynthesis Pathway Enhance AR Development}

Given that exogenous hormone applications may cause artificial physiological responses, mutants with defective ABA synthesis were analyzed. The ABA biosynthesis mutants aba1-1/zep (zeaxanthin epoxidase) [52-55], aba2-1 (xanthoxin dehydrogenase) [56,57], and aba3-1 (molybdenum cofactor sulfurase) [58,59] have been well characterized and are defective in different steps of the ABA biosynthesis pathway [11] (Figure 2A). While each of these mutants have reduced ABA levels, only aba1-1 and aba2-1 formed significantly more ARs compared to the control plants (Figure 2B). The disruption of ABA biosynthesis leads to the accumulation of carotenoid precursors, which have been shown to stimulate anchor root formation [60]. However, Jia et al. (2019) [60] did not observe differences in anchor root formation in $a b a 1-1$ and $a b a 3-1$, suggesting that the enhanced AR rooting in aba1-1 is due to the accumulation of ABA biosynthesis intermediates. The lack of enhanced AR formation in aba3-1 could reflect non-ABA-related functions of ABA3, because it catalyzes the synthesis of a cofactor also required by other enzymes than AAO3 [61], possibly masking any effects of ABA deficiency on AR formation.

\subsection{Molecular Framework of ABA Signaling for Suppression of AR Development}

Because ABA biosynthesis mutants display a pleiotropic phenotype and may accumulate root modulating intermediates, several mutants, defective in downstream ABA signaling, were analyzed. The perception of ABA is mediated by a ternary ABA signaling complex of clade A PP2C protein phosphatases (e.g., ABI1 and ABI2), PYR/PYL/RCAR ABA receptors (hereafter referred to as PYL), and ABA [12-14]. Each subunit of the complex is encoded by a multi-gene family, potentially allowing for high combinatorial complexity [62]. The PYL ABA receptor family in Arabidopsis contains 14 members. As a first attempt to map the individual contribution of members of this gene family, we analyzed single mutants in PYR1/RCAR11, PYL1/RCAR12, PYL2/RCAR14, PYL3/RCAR13, PYL4/RCAR10, PYL5/RCAR8, PYL8/RCAR3, and PYL9/RCAR1. The mutant pyl2-1 showed a significant increase in the number of AR formed (Figure $3 B$ ), which suggests that ABA 
signaling through PYL2 might inhibit AR formation. The mutants pyl1-1 and pyl8-1 showed a tendency (albeit not significant) for increased AR formation (Figure S4), which aligns with the observed PYL1-mediated phosphatase inhibition by E4, the PB analog that also strongly reduced AR formation (Figure S3), and the role for PYL8 in lateral root formation [42]. Except for pyl2-1, other single mutants were not different from control. Given that PB is an antagonist of PYL2, whereas it is an agonist of PYR1 and PYL1, such complexity might contribute to the dose-response curve of PB for AR formation (Figures 1 and 3). Both pentuple and hexuple mutants showed a significant increase in their hypocotyl AR formation numbers, which further suggests that $\mathrm{ABA}$ signaling plays an inhibitory role in $\mathrm{AR}$ formation and underscores the inhibition of AR formation at the $10 \mu \mathrm{M}$ ABA dose (Figure 1).

A

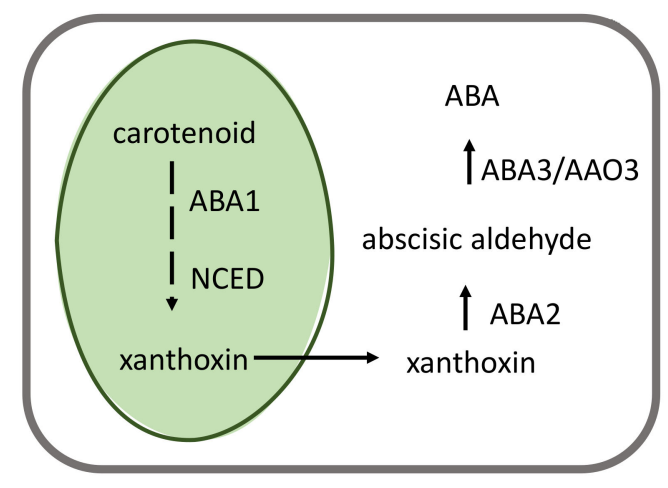

B

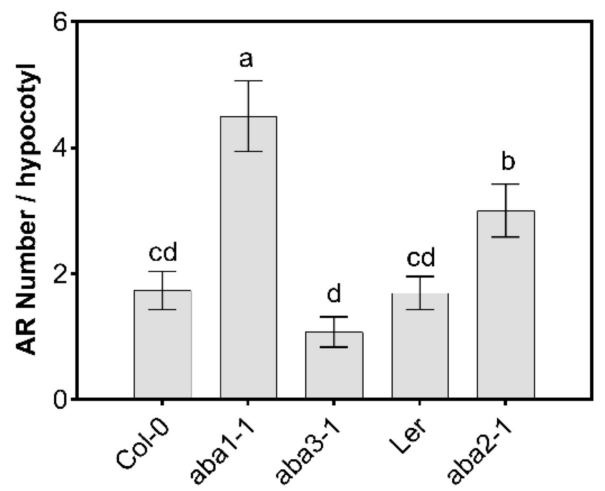

Figure 2. ABA biosynthesis mutants enhance hypocotyl adventitious root formation. (A) Scheme of $A B A$ biosynthetic pathway in higher plants with indication of enzymatic conversions affected by mutants that were analyzed. NCED, 9-cis-epoxycarotenoid dioxygenase; AAO, ABA-aldehyde oxidase. (B) Adventitious root analysis (number per hypocotyl) in ABA biosynthesis mutants. Recordings were conducted 10 days after de-etiolation. Data, represented as mean values \pm se, were obtained from plants grown in three independent experiments $(n=20-25)$. Statistics were calculated using ANOVA, where mean values with different letters are significantly different at $p \leq 0.05$.

ABA sensing via PYR/PYLs results in the inactivation of clade A PP2Cs, which releases SnRK2 protein kinases [18]. The net output of ABA sensing results in the activation of SnRK2s and downstream activation of transcriptional regulation and physiological responses including ion fluxes. Among the early ABA-regulated transcriptional responses are the $A B I 3$ (B3 superfamily) and ABI4 (APETALA2 domain) transcription factors [63,64].

To analyze the putative involvement of PP2C phosphatase activity and TFs in AR formation, we investigated ABA-insensitive abi1-1, abi2-1, abi3-1 and abi4-1 mutants. The $A B I 1$ and $A B I 2$ genes encode for two members of the clade A PP2C family and the dominant mutations abi1-1 and abi2-1 reduce ABA responsiveness in both seeds and vegetative tissues $[65,66]$. The abi3-1 and abi4- 1 mutants contain recessive mutations in ABA-regulated transcription factors $[63,64]$. Each of these ABA-insensitive mutants showed a significant increase in the number of AR (Figure 3D), in support of a role of ABA in AR inhibition. 
A

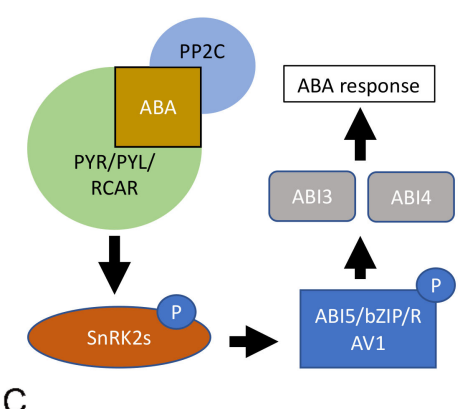

C

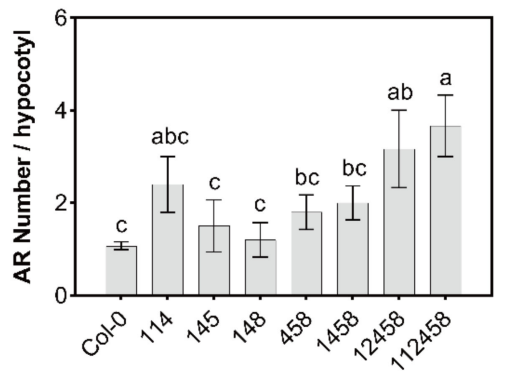

B

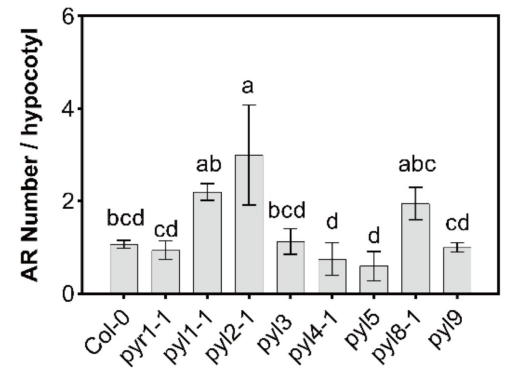

D

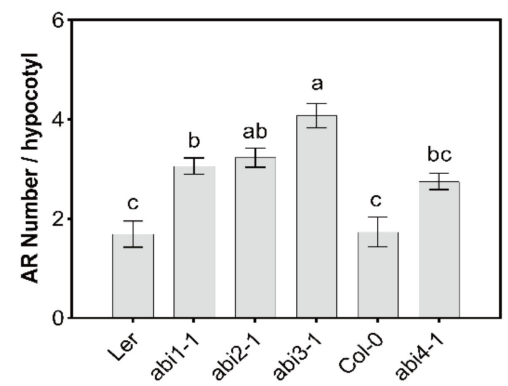

Figure 3. Canonical ABA signaling mutants produce more AR. (A) Schematic representation of ABA signaling pathway in plants. ABA binding to PYR/PYLs triggers interaction with PPC2s (such as ABI1 and ABI2). Consequently, SnRK2 is activated to trigger downstream transcriptional and nontranscriptional responses. Phosphorylation of ABI5-clade bZIPs and RAV1 triggers ABA responses, including expression of ABI3, ABI4 and ABI5. PYL, pyrabactin resistance-related; PP2C, protein phosphatase 2C; SnRK2, sucrose nonfermenting-1-related protein kinase 2; $A B I, A B A$ insensitive; $P$, phosphorylation; RAV1, related to ABI3/VP1; bZIP, basic leucine zipper. The solid line with an arrow indicates direct positive interactions. The solid line with a bar indicates repression. Adventitious root number per hypocotyl for $\mathrm{ABA}$ receptor single mutants $(\mathbf{B})$, ABA receptor higher order mutants (C) and ABA insensitive mutants (D) are shown. Plants were grown for 10 days after stratification following 3 days of etiolation in the dark. AR were quantified after 10 days in light. Data, represented as mean values \pm se, were obtained from plants grown in three independent experiments $(n=20-25)$. Statistics were calculated through ANOVA, where mean values with different letters are significantly different at $p \leq 0.05$.

\section{Conclusions}

Adventitious root formation in the hypocotyl of Arabidopsis was found to be inhibited by ABA, in part controlled by the ABA receptor PYL1 and PYL2. The signaling route for the ABA inhibition of AR formation differs from the control of LR formation, which relies on PYL8. These results provide additional evidence for differential regulation of the AR and LR root initiation processes.

\section{Patents}

Pyrabactin analogues to modulate plant development. Patent number: 9957288.

Supplementary Materials: The following are available online at https:/ /www.mdpi.com/article/10 .3390/genes12081141/s1, Figure S1: Growth and sampling scheme of Arabidopsis thaliana seedlings in the adventitious root assay, Figure S2: Chemical structures of phosphonamide and phosphonate pyrabactin analogues, Figure S3: Phenotypic characterization of novel PB analogs, Figure S4: Phenotype of pyl1-1 and pyl8-1. Figure S5: Effect of PB and PB analogs on PP2C phosphatase activity, Table S1: List of PCR primers. Table S2. Overview of bioactivity scoring of phosphonamide and phosphonate pyrabactin analogs.

Author Contributions: Conceptualization, D.G.; Data curation, C.V.S., P.L.R. and S.V.; Formal analysis, I.V., Y.Z., H.K.T., T.H. and I.G.-M.; Funding acquisition, D.G.; Writing—original draft, Y.Z., 
I.V., S.V. and D.G.; Writing-review and editing, S.V. and D.G. All authors have read and agreed to the published version of the manuscript.

Funding: This research was supported by the Research Foundation Flanders (FWO Vlaanderen, T.H.). IV was supported by the Agency for Innovation by Science and Technology in Flanders (VLAIO) and a fellowship from Ghent University (BOF). Y.Z. was provided with a China Scholarship Council (CSC) grant (No. 201806300036). This work was supported by FWO Vlaanderen (FWO), project numbers 1S48517N and G094619N. Work in the P.L.R. lab was supported by grant BIO2017-82503-R (MICINN).

Data Availability Statement: Raw data supporting reported results are stored on a server in accordance to rules outlined by the data management plan of Ghent University (www.ugent.be/en/ research/datamanagement/before-research/datamanagementplan.htm). Accessed on 31 May 2021.

Acknowledgments: We thank S. Cutler (Riverside, USA) for providing the ABA biosynthesis mutants and ABA signaling mutants.

Conflicts of Interest: The authors declare no conflict of interest.

\section{References}

1. Schroeder, J.I.; Kwak, J.M.; Allen, G.J. Guard cell abscisic acid signalling and engineering drought hardiness in plants. Nature 2001, 410, 327-330. [CrossRef] [PubMed]

2. Yamaguchi-Shinozaki, K.; Shinozaki, K. Transcriptional regulatory networks in cellular responses and tolerance to dehydration and cold stresses. Annu. Rev. Plant Biol. 2006, 57, 781-803. [CrossRef] [PubMed]

3. Jackson, M. Hormones from roots as signals for the shoots of stressed plants. Trends Plant Sci. 1997, 2, 22-28. [CrossRef]

4. Nilson, S.E.; Assmann, S.M. The control of transpiration: Insights from Arabidopsis. Plant Physiol. 2007, 143, 19. [CrossRef]

5. Cutler, S.R.; Rodriguez, P.L.; Finkelstein, R.R.; Abrams, S.R. Abscisic Acid: Emergence of a Core Signaling Network. Annu. Rev. Plant Biol. 2010, 61, 651-679. [CrossRef]

6. Sah, S.K.; Reddy, K.R.; Li, J. Abscisic acid and abiotic stress tolerance in crop plants. Front. Plant Sci. 2016, 7. [CrossRef]

7. Orman-Ligeza, B.; Morris, E.C.; Parizot, B.; Lavigne, T.; Babe, A.; Ligeza, A.; Klein, S.; Sturrock, C.; Xuan, W.; Novak, O.; et al. The xerobranching response represses lateral root formation when roots are not in contact with water. Curr. Biol. 2018, 28, 3165-3173.e5. [CrossRef]

8. Dietrich, D.; Pang, L.; Kobayashi, A.; Fozard, J.A.; Boudolf, V.; Bhosale, R.; Antoni, R.; Nguyen, T.; Hiratsuka, S.; Fujii, N.; et al. Root hydrotropism is controlled via a cortex-specific growth mechanism. Nat. Plants 2017, 3, 17057. [CrossRef]

9. Wasilewska, A.; Vlad, F.; Sirichandra, C.; Redko, Y.; Jammes, F.; Valon, C.; Frey, N.F.d.; Leung, J. An update on abscisic acid signaling in plants and more.... Mol. Plant 2008, 1, 198-217. [CrossRef] [PubMed]

10. Yu, H.; Chen, X.; Hong, Y.-Y.; Wang, Y.; Xu, P.; Ke, S.-D.; Liu, H.-Y.; Zhu, J.-K.; Oliver, D.J.; Xiang, C.-B. Activated expression of an Arabidopsis HD-START protein confers drought tolerance with improved root system and reduced stomatal density. Plant Cell 2008, 20, 1134. [CrossRef]

11. Schwartz, S.H.; Qin, X.; Zeevaart, J.A. Elucidation of the indirect pathway of abscisic acid biosynthesis by mutants, genes, and enzymes. Plant Physiol. 2003, 131, 1591-1601. [CrossRef]

12. Fujii, H.; Chinnusamy, V.; Rodrigues, A.; Rubio, S.; Antoni, R.; Park, S.-Y.; Cutler, S.R.; Sheen, J.; Rodriguez, P.L.; Zhu, J.-K. In vitro reconstitution of an abscisic acid signalling pathway. Nature 2009, 462, 660-664. [CrossRef]

13. Ma, Y.; Szostkiewicz, I.; Korte, A.; Moes, D.; Yang, Y.; Christmann, A.; Grill, E. Regulators of PP2C phosphatase activity function as abscisic acid sensors. Science 2009, 324, 1064. [CrossRef]

14. Park, S.-Y.; Fung, P.; Nishimura, N.; Jensen, D.R.; Fujii, H.; Zhao, Y.; Lumba, S.; Santiago, J.; Rodrigues, A.; Chow, T.-f.F.; et al. Abscisic acid inhibits type 2C protein phosphatases via the PYR/PYL family of START proteins. Science 2009, 324, 1068. [CrossRef]

15. Nishimura, N.; Yoshida, T.; Kitahata, N.; Asami, T.; Shinozaki, K.; Hirayama, T. ABA-Hypersensitive Germination1 encodes a protein phosphatase 2C, an essential component of abscisic acid signaling in Arabidopsis seed. Plant J. 2007, 50, 935-949. [CrossRef] [PubMed]

16. Lin, Z.; Li, Y.; Zhang, Z.; Liu, X.; Hsu, C.-C.; Du, Y.; Sang, T.; Zhu, C.; Wang, Y.; Satheesh, V. A RAF-SnRK2 kinase cascade mediates early osmotic stress signaling in higher plants. Nat. Commun. 2020, 11, 1-10. [CrossRef] [PubMed]

17. Lin, Z.; Li, Y.; Wang, Y.; Liu, X.; Ma, L.; Zhang, Z.; Mu, C.; Zhang, Y.; Peng, L.; Xie, S. Initiation and amplification of SnRK2 activation in abscisic acid signaling. Nat. Commun. 2021, 12, 1-13. [CrossRef] [PubMed]

18. Munemasa, S.; Hauser, F.; Park, J.; Waadt, R.; Brandt, B.; Schroeder, J.I. Mechanisms of abscisic acid-mediated control of stomatal aperture. Curr. Opin. Plant Biol. 2015, 28, 154-162. [CrossRef]

19. Zhang, J.; Hafeez, M.T.; Di, D.; Wu, L.; Zhang, L. Precise control of ABA signaling through post-translational protein modification. Plant Growth Regul. 2019, 88, 99-111. [CrossRef]

20. Zhang, D.-P. Abscisic Acid: Metabolism, Transport and Signaling; Springer: Berlin/Heidelberg, Germany, 2014.

21. Hubbard, K.E.; Nishimura, N.; Hitomi, K.; Getzoff, E.D.; Schroeder, J.I. Early abscisic acid signal transduction mechanisms: Newly discovered components and newly emerging questions. Genes Dev. 2010, 24, 1695-1708. [CrossRef] [PubMed] 
22. Raghavendra, A.S.; Gonugunta, V.K.; Christmann, A.; Grill, E. ABA perception and signalling. Trends Plant Sci. 2010, 15, 395-401. [CrossRef]

23. Chen, K.; Li, G.J.; Bressan, R.A.; Song, C.P.; Zhu, J.K.; Zhao, Y. Abscisic acid dynamics, signaling, and functions in plants. J. Integr. Plant Biol. 2020, 62, 25-54. [CrossRef] [PubMed]

24. Fujita, Y.; Nakashima, K.; Yoshida, T.; Katagiri, T.; Kidokoro, S.; Kanamori, N.; Umezawa, T.; Fujita, M.; Maruyama, K.; Ishiyama, K.; et al. Three SnRK2 protein kinases are the main positive regulators of abscisic acid signaling in response to water stress in Arabidopsis. Plant Cell Physiol. 2009, 50, 2123-2132. [CrossRef] [PubMed]

25. Nakashima, K.; Fujita, Y.; Kanamori, N.; Katagiri, T.; Umezawa, T.; Kidokoro, S.; Maruyama, K.; Yoshida, T.; Ishiyama, K.; Kobayashi, M.; et al. Three Arabidopsis SnRK2 protein kinases, SRK2D/SnRK2.2, SRK2E/SnRK2.6/OST1 and SRK2I/SnRK2.3, involved in ABA signaling are essential for the control of seed development and dormancy. Plant Cell Physiol. 2009, 50, 1345-1363. [CrossRef]

26. Kobayashi, Y.; Murata, M.; Minami, H.; Yamamoto, S.; Kagaya, Y.; Hobo, T.; Yamamoto, A.; Hattori, T. Abscisic acid-activated SNRK2 protein kinases function in the gene-regulation pathway of ABA signal transduction by phosphorylating ABA response element-binding factors. Plant J. 2005, 44, 939-949. [CrossRef]

27. Chandrasekaran, U.; Luo, X.; Zhou, W.; Shu, K. Multifaceted signaling networks mediated by abscisic acid insensitive 4. Plant Commun. 2020, 1, 100040. [CrossRef] [PubMed]

28. Feng, C.Z.; Chen, Y.; Wang, C.; Kong, Y.H.; Wu, W.H.; Chen, Y.F. Arabidopsis RAV1 transcription factor, phosphorylated by SnRK2 kinases, regulates the expression of ABI3, ABI4, and ABI5 during seed germination and early seedling development. Plant J. 2014, 80, 654-668. [CrossRef] [PubMed]

29. Antoni, R.; Gonzalez-Guzman, M.; Rodriguez, L.; Peirats-Llobet, M.; Pizzio, G.A.; Fernandez, M.A.; De Winne, N.; De Jaeger, G.; Dietrich, D.; Bennett, M.J.; et al. PYRABACTIN RESISTANCE1-LIKE8 plays an important role for the regulation of abscisic acid signaling in root. Plant Physiol. 2013, 161, 931-941. [CrossRef]

30. Zhao, Y.; Xing, L.; Wang, X.; Hou, Y.-J.; Gao, J.; Wang, P.; Duan, C.-G.; Zhu, X.; Zhu, J.-K. The ABA receptor PYL8 promotes lateral root growth by enhancing MYB77-dependent transcription of auxin-responsive genes. Sci. Signal. 2014, 7, ra53. [CrossRef]

31. Belda-Palazon, B.; Gonzalez-Garcia, M.-P.; Lozano-Juste, J.; Coego, A.; Antoni, R.; Julian, J.; Peirats-Llobet, M.; Rodriguez, L.; Berbel, A.; Dietrich, D. PYL8 mediates ABA perception in the root through non-cell-autonomous and ligand-stabilization-based mechanisms. Proc. Natl. Acad. Sci. USA 2018, 115, E11857-E11863. [CrossRef]

32. Dittrich, M.; Mueller, H.M.; Bauer, H.; Peirats-Llobet, M.; Rodriguez, P.L.; Geilfus, C.-M.; Carpentier, S.C.; Al Rasheid, K.A.; Kollist, H.; Merilo, E. The role of Arabidopsis ABA receptors from the PYR/PYL/RCAR family in stomatal acclimation and closure signal integration. Nat. Plants 2019, 5, 1002-1011. [CrossRef] [PubMed]

33. García-Andrade, J.; González, B.; Gonzalez-Guzman, M.; Rodriguez, P.L.; Vera, P. The role of ABA in plant immunity is mediated through the PYR1 receptor. Int. J. Mol. Sci. 2020, 21, 5852. [CrossRef]

34. Peterson, F.C.; Burgie, E.S.; Park, S.Y.; Jensen, D.R.; Weiner, J.J.; Bingman, C.A.; Chang, C.E.; Cutler, S.R.; Phillips, G.N., Jr.; Volkman, B.F. Structural basis for selective activation of ABA receptors. Nat. Struct. Mol. Biol. 2010, 17, 1109-1113. [CrossRef] [PubMed]

35. Melcher, K.; Xu, Y.; Ng, L.M.; Zhou, X.E.; Soon, F.F.; Chinnusamy, V.; Suino-Powell, K.M.; Kovach, A.; Tham, F.S.; Cutler, S.R.; et al. Identification and mechanism of ABA receptor antagonism. Nat. Struct. Mol. Biol. 2010, 17, 1102-1108. [CrossRef] [PubMed]

36. Okamoto, M.; Peterson, F.C.; Defries, A.; Park, S.-Y.; Endo, A.; Nambara, E.; Volkman, B.F.; Cutler, S.R. Activation of dimeric ABA receptors elicits guard cell closure, ABA-regulated gene expression, and drought tolerance. Proc. Natl. Acad. Sci. USA 2013, 110, 12132-12137. [CrossRef]

37. Vaidya, A.S.; Helander, J.D.M.; Peterson, F.C.; Elzinga, D.; Dejonghe, W.; Kaundal, A.; Park, S.-Y.; Xing, Z.; Mega, R.; Takeuchi, J.; et al. Dynamic control of plant water use using designed ABA receptor agonists. Science 2019, 366, eaaw8848. [CrossRef] [PubMed]

38. Dejonghe, W.; Okamoto, M.; Cutler, S.R. Small molecule probes of ABA biosynthesis and signaling. Plant Cell Physiol. 2018, 59, 1490-1499. [CrossRef]

39. Helander, J.D.; Vaidya, A.S.; Cutler, S.R. Chemical manipulation of plant water use. Bioorg. Med. Chem. 2016, 24, 493-500. [CrossRef]

40. Miao, R.; Yuan, W.; Wang, Y.; Garcia-Maquilon, I.; Dang, X.; Li, Y.; Zhang, J.; Zhu, Y.; Rodriguez, P.L.; Xu, W. Low ABA concentration promotes root growth and hydrotropism through relief of ABA INSENSITIVE 1-mediated inhibition of plasma membrane H+-ATPase 2. Sci. Adv. 2021, 7, eabd4113. [CrossRef]

41. Duan, L.; Dietrich, D.; Ng, C.H.; Chan, P.M.; Bhalerao, R.; Bennett, M.J.; Dinneny, J.R. Endodermal ABA signaling promotes lateral root quiescence during salt stress in Arabidopsis seedlings. Plant Cell 2013, 25, 324-341. [CrossRef]

42. Xing, L.; Zhao, Y.; Gao, J.; Xiang, C.; Zhu, J.K. The ABA receptor PYL9 together with PYL8 plays an important role in regulating lateral root growth. Sci. Rep. 2016, 6, 27177. [CrossRef] [PubMed]

43. Lakehal, A.; Bellini, C. Control of adventitious root formation: Insights into synergistic and antagonistic hormonal interactions. Physiol. Plant 2019, 165, 90-100. [CrossRef]

44. Trinh, H.K.; Verstraeten, I.; Geelen, D. In vitro assay for induction of adventitious rooting on intact Arabidopsis hypocotyls. In Root Development; Springer: Berlin/Heidelberg, Germany, 2018; pp. 95-102. 
45. Van Overtveldt, M.; Heugebaert, T.S.; Verstraeten, I.; Geelen, D.; Stevens, C.V. Phosphonamide pyrabactin analogues as abscisic acid agonists. Organ. Biomol. Chem. 2015, 13, 5260-5264. [CrossRef]

46. Gonzalez-Guzman, M.; Pizzio, G.A.; Antoni, R.; Vera-Sirera, F.; Merilo, E.; Bassel, G.W.; Fernández, M.A.; Holdsworth, M.J.; Perez-Amador, M.A.; Kollist, H. Arabidopsis PYR/PYL/RCAR receptors play a major role in quantitative regulation of stomatal aperture and transcriptional response to abscisic acid. Plant Cell 2012, 24, 2483-2496. [CrossRef] [PubMed]

47. Ubeda-Tomas, S.; Swarup, R.; Coates, J.; Swarup, K.; Laplaze, L.; Beemster, G.T.; Hedden, P.; Bhalerao, R.; Bennett, M.J. Root growth in Arabidopsis requires gibberellin/DELLA signalling in the endodermis. Nat. Cell Biol. 2008, 10, 625-628. [CrossRef] [PubMed]

48. Harris, J.M. Abscisic Acid: Hidden Architect of Root System Structure. Plants 2015, 4, 548-572. [CrossRef]

49. Geng, Y.; Wu, R.; Wee, C.W.; Xie, F.; Wei, X.; Chan, P.M.; Tham, C.; Duan, L.; Dinneny, J.R. A spatio-temporal understanding of growth regulation during the salt stress response in Arabidopsis. Plant Cell 2013, 25, 2132-2154. [CrossRef]

50. Steffens, B.; Wang, J.; Sauter, M. Interactions between ethylene, gibberellin and abscisic acid regulate emergence and growth rate of adventitious roots in deepwater rice. Planta 2006, 223, 604-612. [CrossRef]

51. Nguyen, T.-N.; Tuan, P.A.; Mukherjee, S.; Son, S.; Ayele, B.T. Hormonal regulation in adventitious roots and during their emergence under waterlogged conditions in wheat. J. Exp. Bot. 2018, 69, 4065-4082. [CrossRef]

52. Karssen, C.M.; Brinkhorst-van der Swan, D.L.; Breekland, A.E.; Koornneef, M. Induction of dormancy during seed development by endogenous abscisic acid: Studies on abscisic acid deficient genotypes of Arabidopsis thaliana (L.) Heynh. Planta 1983, 157, 158-165. [CrossRef]

53. Rock, C.D.; Zeevaart, J.A. The aba mutant of Arabidopsis thaliana is impaired in epoxy-carotenoid biosynthesis. Proc. Natl. Acad. Sci. USA 1991, 88, 7496-7499. [CrossRef]

54. Niyogi, K.K.; Grossman, A.R.; Bjorkman, O. Arabidopsis mutants define a central role for the xanthophyll cycle in the regulation of photosynthetic energy conversion. Plant Cell 1998, 10, 1121-1134. [CrossRef]

55. Xiong, L.; Lee, H.; Ishitani, M.; Zhu, J.K. Regulation of osmotic stress-responsive gene expression by the LOS6/ABA1 locus in Arabidopsis. J. Biol. Chem. 2002, 277, 8588-8596. [CrossRef] [PubMed]

56. Cheng, W.H.; Endo, A.; Zhou, L.; Penney, J.; Chen, H.C.; Arroyo, A.; Leon, P.; Nambara, E.; Asami, T.; Seo, M.; et al. A unique short-chain dehydrogenase/reductase in Arabidopsis glucose signaling and abscisic acid biosynthesis and functions. Plant Cell 2002, 14, 2723-2743. [CrossRef]

57. Gonzalez-Guzman, M.; Apostolova, N.; Belles, J.M.; Barrero, J.M.; Piqueras, P.; Ponce, M.R.; Micol, J.L.; Serrano, R.; Rodriguez, P.L. The short-chain alcohol dehydrogenase ABA2 catalyzes the conversion of xanthoxin to abscisic aldehyde. Plant Cell 2002, 14, 1833-1846. [CrossRef]

58. Schwartz, S.H.; Leon-Kloosterziel, K.M.; Koornneef, M.; Zeevaart, J.A. Biochemical characterization of the aba2 and aba3 mutants in Arabidopsis thaliana. Plant Physiol. 1997, 114, 161-166. [CrossRef] [PubMed]

59. Xiong, L.; Ishitani, M.; Lee, H.; Zhu, J.K. The Arabidopsis LOS5/ABA3 locus encodes a molybdenum cofactor sulfurase and modulates cold stress- and osmotic stress-responsive gene expression. Plant Cell 2001, 13, 2063-2083. [CrossRef]

60. Jia, K.P.; Dickinson, A.J.; Mi, J.; Cui, G.; Xiao, T.T.; Kharbatia, N.M.; Guo, X.; Sugiono, E.; Aranda, M.; Blilou, I.; et al. Anchorene is a carotenoid-derived regulatory metabolite required for anchor root formation in Arabidopsis. Sci. Adv. 2019, 5, eaaw6787. [CrossRef]

61. Watanabe, S.; Sato, M.; Sawada, Y.; Tanaka, M.; Matsui, A.; Kanno, Y.; Hirai, M.Y.; Seki, M.; Sakamoto, A.; Seo, M. Arabidopsis molybdenum cofactor sulfurase ABA3 contributes to anthocyanin accumulation and oxidative stress tolerance in ABA-dependent and independent ways. Sci. Rep. 2018, 8, 16592. [CrossRef]

62. Tischer, S.V.; Wunschel, C.; Papacek, M.; Kleigrewe, K.; Hofmann, T.; Christmann, A.; Grill, E. Combinatorial interaction network of abscisic acid receptors and coreceptors from Arabidopsis thaliana. Proc. Natl. Acad. Sci. USA 2017, 114, 10280-10285. [CrossRef]

63. Parcy, F.; Valon, C.; Raynal, M.; Gaubier-Comella, P.; Delseny, M.; Giraudat, J. Regulation of gene expression programs during Arabidopsis seed development: Roles of the ABI3 locus and of endogenous abscisic acid. Plant Cell 1994, 6, 1567-1582. [CrossRef]

64. Finkelstein, R.R.; Wang, M.L.; Lynch, T.J.; Rao, S.; Goodman, H.M. The Arabidopsis abscisic acid response locus ABI4 encodes an APETALA 2 domain protein. Plant Cell 1998, 10, 1043-1054. [CrossRef]

65. Gosti, F.; Beaudoin, N.; Serizet, C.; Webb, A.A.; Vartanian, N.; Giraudat, J. ABI1 protein phosphatase 2C is a negative regulator of abscisic acid signaling. Plant Cell 1999, 11, 1897-1910. [CrossRef] [PubMed]

66. Merlot, S.; Gosti, F.; Guerrier, D.; Vavasseur, A.; Giraudat, J. The ABI1 and ABI2 protein phosphatases $2 \mathrm{C}$ act in a negative feedback regulatory loop of the abscisic acid signalling pathway. Plant J. 2001, 25, 295-303. [CrossRef] [PubMed] 